University of Nebraska - Lincoln

DigitalCommons@University of Nebraska - Lincoln

Faculty Publications from the Department of Electrical \& Computer Engineering, Department Electrical and Computer Engineering

2009

\title{
Voltage Analysis of Distribution Systems with DFIG Wind Turbines
}

\author{
Baohua Dong \\ University of Nebraska-Lincoln, baohua.dong@gmail.com \\ Sohrab Asgarpoor \\ University of Nebraska-Lincoln, sasgarpoor1@unl.edu \\ Wei Qiao \\ University of Nebraska-Lincoln, wqiao@engr.unl.edu
}

Follow this and additional works at: https://digitalcommons.unl.edu/electricalengineeringfacpub

Part of the Electrical and Computer Engineering Commons

Dong, Baohua; Asgarpoor, Sohrab; and Qiao, Wei, "Voltage Analysis of Distribution Systems with DFIG Wind Turbines" (2009). Faculty Publications from the Department of Electrical and Computer Engineering. 137.

https://digitalcommons.unl.edu/electricalengineeringfacpub/137

This Article is brought to you for free and open access by the Electrical \& Computer Engineering, Department of at DigitalCommons@University of Nebraska - Lincoln. It has been accepted for inclusion in Faculty Publications from the Department of Electrical and Computer Engineering by an authorized administrator of DigitalCommons@University of Nebraska - Lincoln. 


\title{
Voltage Analysis of Distribution Systems with DFIG Wind Turbines
}

\author{
Baohua Dong, Sohrab Asgarpoor, and Wei Qiao \\ Department of Electrical Engineering \\ University of Nebraska-Lincoln \\ Lincoln, Nebraska 68588-0511, USA \\ sasgarpoor1@unl.edu; wqiao@engr.unl.edu
}

\begin{abstract}
Wind energy is becoming the most viable renewable energy source mainly because of the growing concerns over carbon emissions and uncertainties in fossil fuel supplies and the government policy impetus. The increasing penetration of wind power in distribution systems may significantly affect voltage stability of the systems, particularly during wind turbine cut-in and cut-off disturbances. Currently, doubly fed induction generator wind turbine (DFIG-WT) is the most popular wind turbine. This paper investigates the issues of voltage stability improvement and grid-loss reduction of distribution systems which include DFIG-WTs under unbalanced heavy loading conditions. Simulation studies are carried out in IEEE 34-bus test system using DIgSILENT software to examine these issues during steady-state and transient operations of the system. Optimal locations of the WTs are determined based on this analysis. A new index (system unbalanced voltage variance) is proposed to evaluate system unbalanced voltage. The dynamic impacts between WTs and motor loads are also examined.
\end{abstract}

Index Terms-Voltage stability, doubly-fed induction generator (DFIG), distribution systems, optimal location, wind turbines, grid loss, unbalanced power flow.

\section{INTRODUCTION}

$\mathrm{W}$ ind energy is a clean, renewable and indigenous energy resource. Wind power capacity is annually added over $20 \%$ in recent five years because of its relatively low MWh cost [1]. Wind power could be combined with appropriate reactive power compensations to improve the operation of the electricity distribution systems. Some of the often-quoted benefits include the following [2]:

1) Emergency backup during sustained utility outages.

2) Voltage support.

3) Loss reduction.

4) Improved utility system reliability.

5) Distribution capacity release.

6) Potential utility capacity addition deferrals.

On the other hand, the integration of wind power may cause some additional problems in voltage and frequency regulation, reactive power compensation, power quality (e.g., flicker and harmonics) and protection of the distribution systems [3]-[8].

In general, reactive power compensations are very important to WTs. Lack of sufficient reactive power may result in voltages typically lower (0.05-0.1p.u.) than normal voltages [3]. The most serious disturbances in system operation occur during the cut-in and cut-off of the WTs from the grid, grid faults, etc. During the transient state after a disturbance, the flicker level, harmonics, frequency and voltage fluctuations sharply increase; in some autonomous power systems, the frequency and voltage level would decrease more than $1 \mathrm{~Hz}$ and more than 0.05-0.1p.u [6], respectively. The WTs with large capacities could possibly change the original power flow direction and the protection systems need to be set new "pick-up" value to make the breakers work properly. Therefore, not only the protection systems, but also the interconnection requirements and islanding operation should be considered more for system stability [9].

With the recent development in power electronics, the DFIG-WTs become very popular. Comparing to traditional squirrel-cage induction generator wind turbines, the major advantages of DFIG are that they can operate in a higher wind speed range and produce or consume reactive power through the magnetization provided by the rotor-side converter. DFIGWTs also offer other advantages, such as [10]:

1) Low converter and inverter cost, because the converter's rating is typically $25 \%$ of the total power rating of the DFIG.

2) Capability for power-factor control and reactive power compensation.

3) Reduced cost of the inverter filters.

4) Improved WTs efficiency.

Most work in this area mainly focused on the research and simulation of a simple test system with a DFIG-WT. This article is concerned with voltage analysis of a moderate size system, i.e., the IEEE 34-bus test system [11], which includes DFIG-WTs. Simulation studies are carried out in DIgSILENT software [12] to investigate effect of WTs on the steady-state and transient behavior of the distribution systems

This article is organized as follows. Section II-A presents several case studies during steady state using the test system which has a single DFIG-WT and provides a new index to evaluate system unbalanced voltages. Section II-B compares the steady-state impacts between a single large-DFIG system and a multiple small-DFIG system. Section II-C compares the transient impacts between the two systems. Section III analyzes the simulation results and provides some discussions.

\section{SYSTEM SIMULATION}

The IEEE 34-bus test system shown in Fig. 1 is a typical radial-distribution system and the simulation system is constructed with DIgSILENT using detailed data from [11]. 
The system has two auto-regulators which regulate the voltage in \pm 0.05 p.u. range and one auto-transformer which controls the voltage in \pm 0.05 p.u.range. They are set to automatic-tap adjustment for the basic case position because their initial tap position has a significant role on the system voltage regulation. The distributed loads are handled as split loads with half on each bus.

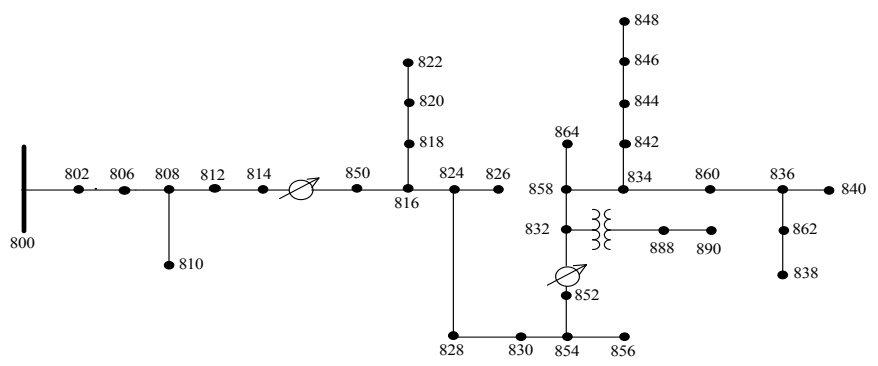

Fig. 1. IEEE 34-bus test system.

In the test system, bus 800 is connected to the grid and bus 890 and 844 are the load centers. The voltage at bus 890 is usually low because the line between bus 888 and 890 is relatively long. Several shunt capacitors are added at buses 844 and 848 to totally compensate for reactive power 0.75 MVar. The two regulators work together to control bus 852 voltage and it plays an essential role in system voltage control. In light loading conditions given by [11], the total unbalanced load is $1.769 \mathrm{MW}$ and 1.044 MVar; the grid loss is $0.27 \mathrm{MW}$; the voltages at buses 852 and 890 are 0.965 p.u. and 0.921 p.u., respectively. Other bus voltages are in the range of $0.95-$ 1.05 p.u. Bus 890 is apparently the weakest bus.

\section{A. Basic case studies with a single DFIG-WT connected to the test system}

The average bus voltage is usually used to evaluate the system voltage profile [13]. However, it does not reasonably reflect the system voltage unbalanced factor. A new index (system unbalanced voltage variance) is proposed to evaluate system voltage as follows:

$$
\begin{gathered}
\bar{V}=\sum_{i=1}^{N} \frac{V_{i A}+V_{i B}+V_{i C}}{3 N} \\
s^{2}=\sum_{i=1}^{N} \frac{\left(V_{i A}-1.05\right)^{2}+\left(V_{i B}-1.05\right)^{2}+\left(V_{i C}-1.05\right)^{2}}{3 N}
\end{gathered}
$$

where $V_{i A}, V_{i B}, V_{i C}$ are the 3-phase voltages at bus $\mathrm{i} ; \mathrm{N}$ is the system bus number; $\bar{V}$ is the system average voltage; $s^{2}$ is the system unbalanced voltage variance (using 1.05 to replace $\bar{V}$ for a higher accuracy).

If a constant load (1.0 MW, 0.1 MVar) is added at the terminal bus 840 and reactive power compensation $(0.30$ MVar) is added at bus 890, the regulator 2 and transformer reach the maximum tap position. Bus 852 voltage is 0.909 p.u. and the grid loss is $0.71 \mathrm{MW}$. If the tap of the regulator 1 is manually increased, the three-phase voltage at bus 890 changes and becomes more unbalanced. Therefore, this unbalanced heavy loading condition is selected as the base case for the rest simulation studies.

The single 1.5-MW DFIG-WT (DIgSILENT provided) is connected at various bus locations to evaluate which location provides the most system-voltage improvement and the most reduction in grid loss. In order to easily analyze the difference between the average bus voltage and the system unbalanced voltage variance, an index (1.05-s) is selected. The result is shown in Figures 2 and 3.

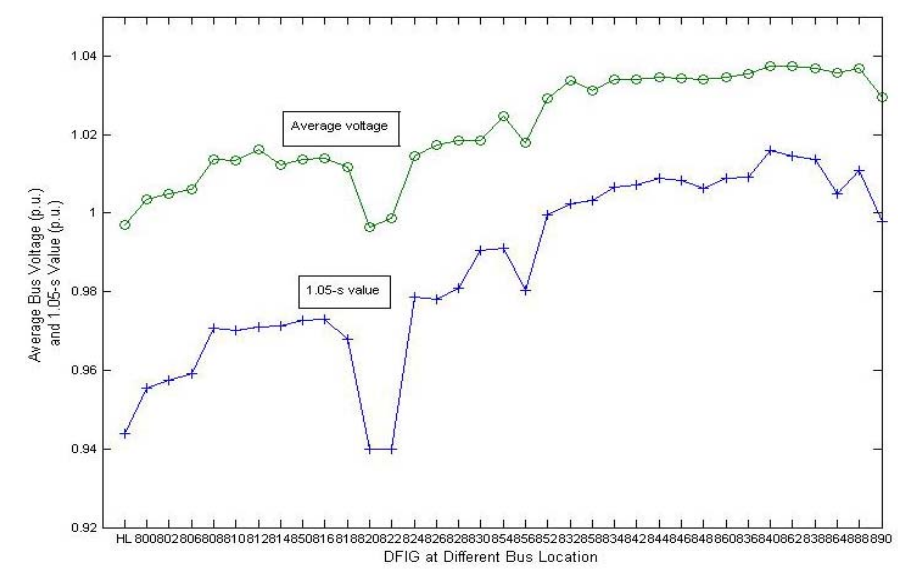

Fig. 2. Average bus voltage and 1.05 -s value when a $1.5-\mathrm{MW}$ DFIG-WT is placed at different locations.

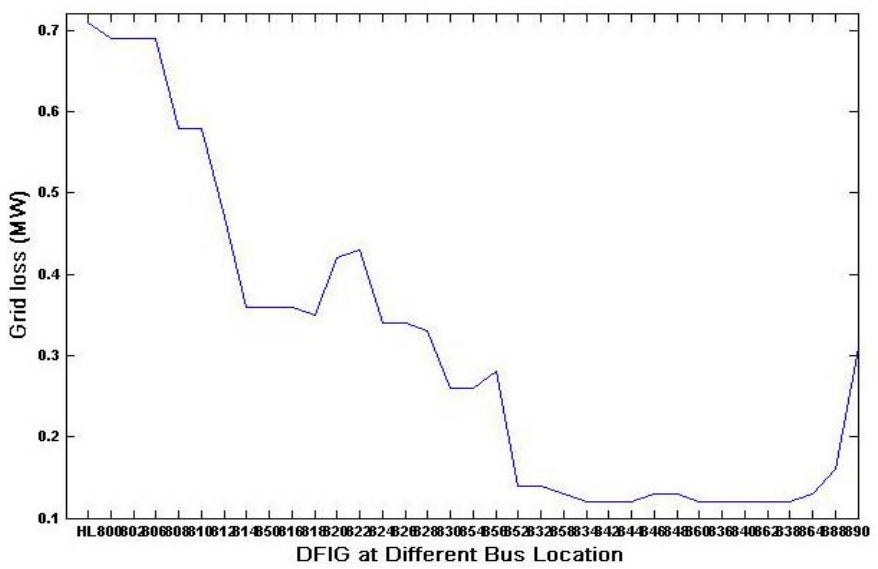

Fig. 3. Grid loss when a 1.5-MW DFIG-WT is placed at different locations.

With the DFIG's location closer to the load center (buses 840,844 , and 890), the voltage profile is improved more and the grid losses greatly reduced. The average bus voltage and 1.05 -s value basically have the same trend. However, the latter has a higher accuracy to evaluate the unbalanced system voltage improvement, especially where DFIG is connected at buses 840 and 888 . The average bus voltage index could not reflect the degree of voltage unbalance.

At bus $840,1.05$-s value reaches the maximum value while at buses $834,842,844,860,836,840,862$, and 838 , the grid losses is minimum. Therefore, the optimal location is determined to be bus 840 .

The transformer adjusts voltage range to increase from \pm 0.05 p.u. to $\pm 0.1 p . u$. when DFIG is connected at bus 890 because it is a low-voltage bus $(4.16 \mathrm{KV})$, otherwise more voltage $(0.13$ p.u.) drops in the long low-voltage line between 
buses 890 and 888 . If more power transfers through lowvoltage line to the grid, the grid loss increases to $0.30 \mathrm{MW}$. If the WT is large, it is better to install it at a high voltage transmission line and closer to the load center. It is consistent with the common sense. However, if the load centers are far away from each other or the loads are more distributed, the optimal location should be carefully calculated by a formulating multi-objective optimization:

$$
\min : p_{s} k_{s} s_{i}+\left(1-p_{s}\right) P_{\text {lossi }},(i \in \text { different cases })
$$

where $s_{i}$ and $P_{\text {lossi }}$ are the different cases $s_{i}$ and grid loss; $k_{s}$ is used to adjust them on the same number class; $p_{s}$ is the weight associated with the case $s_{i} ; 1-p_{s}$ is the weight of $P_{\text {lossi }}$.

\section{B. Comparison of steady-state impacts between a single large-DFIG system and a multiple small-DFIG system}

Two smaller DFIG-WTs (0.75 MW) are added at buses 832 and 836 to compare the steady-state impacts with a single DFIG-WT (1.5 MW) at different buses in the system. The results are shown in Fig. 4.

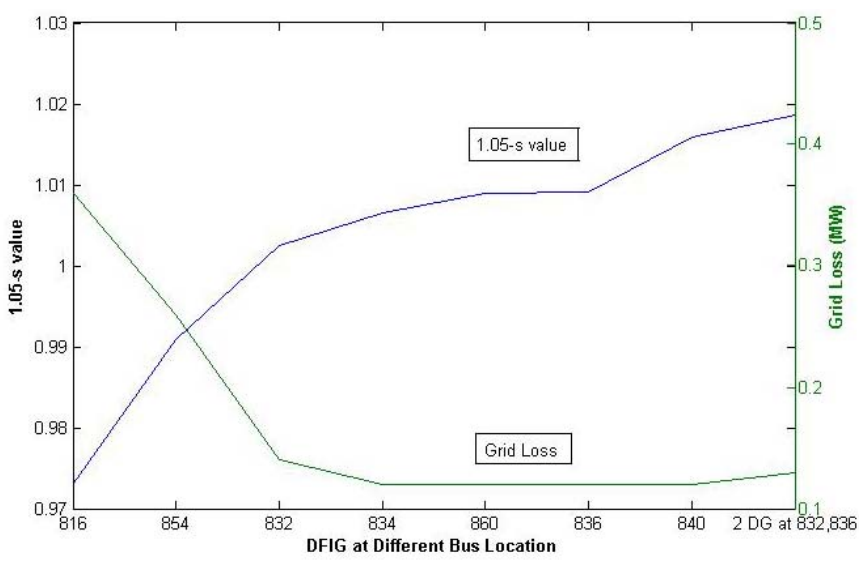

Fig. 4. Comparison of grid loss and 1.05-s value between a single large-DFIG system and multiple small-DFIG system.

As shown, the multiple small-DFIG system could provide higher 1.05 -s value and better system voltage improvement. Its grid loss is almost the same as the optimal grid loss of the single large-DFIG system. Moreover, the optimal locations of the multiple small-DFIG system could be calculated and its grid loss would be less. Therefore, the multiple small-DFIG system would be higher evaluated than the single large-DFIG system.

\section{Comparison of transient impacts between a single large- DFIG system and a multiple small-DFIG system}

Short circuits, cutting load (including constant $\mathrm{Z}$ load and motors), and DFIG cut-off or cut-in are the major disturbances in distribution systems. The load-center voltage waveforms are determined when subjected to these disturbances. However, the size of some dynamic models is adjusted to provide a stable convergence.

1) Case C1: the single DFIG $(0.75 \mathrm{MW})$ is placed at bus 856; reactive power compensation is adjusted to $0.60 \mathrm{MVar}$ at bus 890 and the load at bus 890 is adjusted to $0.25 \mathrm{MW}$ motor. These following disturbances occur in sequence:

At $\mathrm{t}=0.18 \mathrm{~s}$, a 3 -phase short circuit (using fault impedance $\mathrm{Z}=15+\mathrm{j} 40 \mathrm{Ohm}$ to control the voltage of bus 840 at 0.5 p.u. in the fault) at bus 862 ;

At $\mathrm{t}=0.28 \mathrm{~s}$, clear short circuit;

At $\mathrm{t}=0.35 \mathrm{~s}$, cut the $1-\mathrm{MW}$ load (at bus 840);

At $\mathrm{t}=0.45 \mathrm{~s}$, recover the load;

At $\mathrm{t}=0.65 \mathrm{~s}$, cut the motor;

At $\mathrm{t}=0.8 \mathrm{~s}$, cut-in the motor;

At $\mathrm{t}=1 \mathrm{~s}$, cut-off DFIG;

At $\mathrm{t}=1.18 \mathrm{~s}$, cut-in DFIG.

The results are shown in Figures 5 and 6.

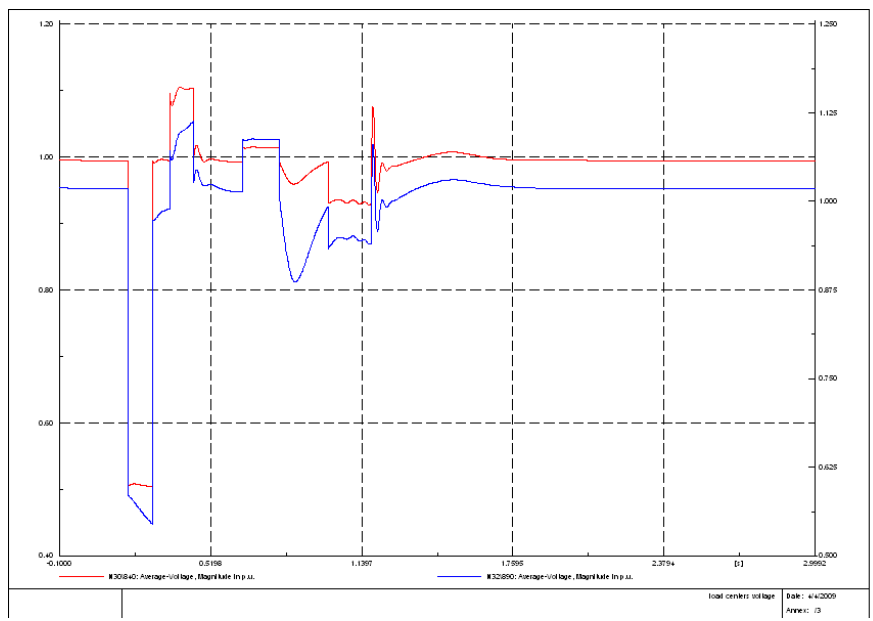

Fig. 5. The voltages of buses 840 and 890 for case $\mathrm{C} 1$

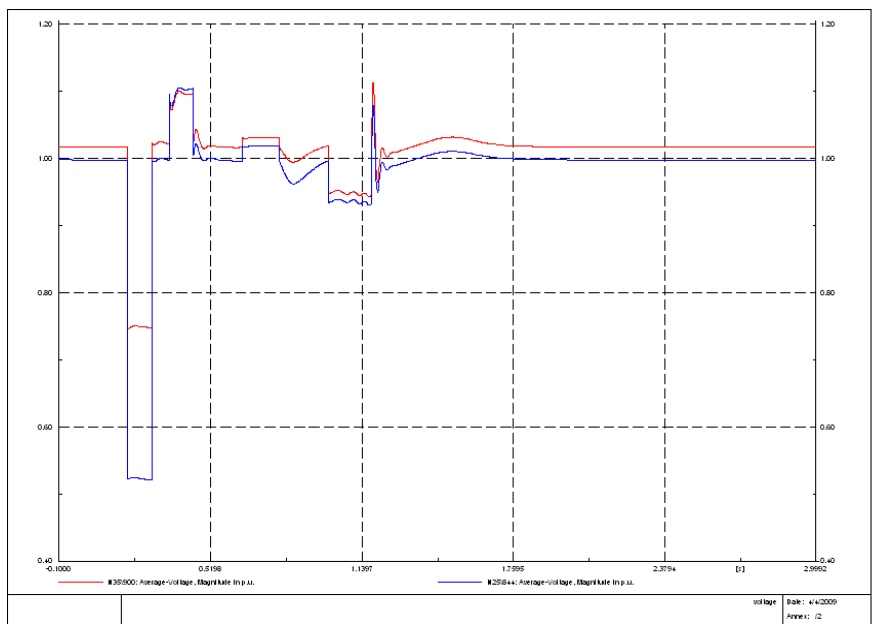

Fig. 6. The voltages of buses 844 and 900 (connected DFIG and bus 856 ) for case $\mathrm{C} 1$

From Figures 5 and 6 which are shown, the load-center voltage fluctuates about 0.1 p.u. because of the cut-off of the large load which affects almost all bus voltages. The dynamic impacts of cut-in DFIG and the motor are larger than cut-off and the motor has a significant role on the local bus voltage. Therefore, the low voltage bus 890 is the most fluctuant, and considered as a weak bus.

2) Case $\mathrm{C} 2$ : Based on the condition of case $\mathrm{C} 1$, these following disturbances occur simultaneously: 
At $\mathrm{t}=0.18 \mathrm{~s}, 3$-phase short circuit at bus 862 ;

At $\mathrm{t}=0.2 \mathrm{~s}$, cut the motor;

At $\mathrm{t}=0.25 \mathrm{~s}$, cut-off DFIG;

At $\mathrm{t}=0.38 \mathrm{~s}$, clear short circuit;

At $\mathrm{t}=0.43 \mathrm{~s}$, cut-in DFIG;

At $\mathrm{t}=0.5 \mathrm{~s}$, cut-in the motor;

At $\mathrm{t}=1.4 \mathrm{~s}$, cut the large load;

At $\mathrm{t}=1.6 \mathrm{~s}$, recover the load.

The results are shown in Figures 7 and 8.

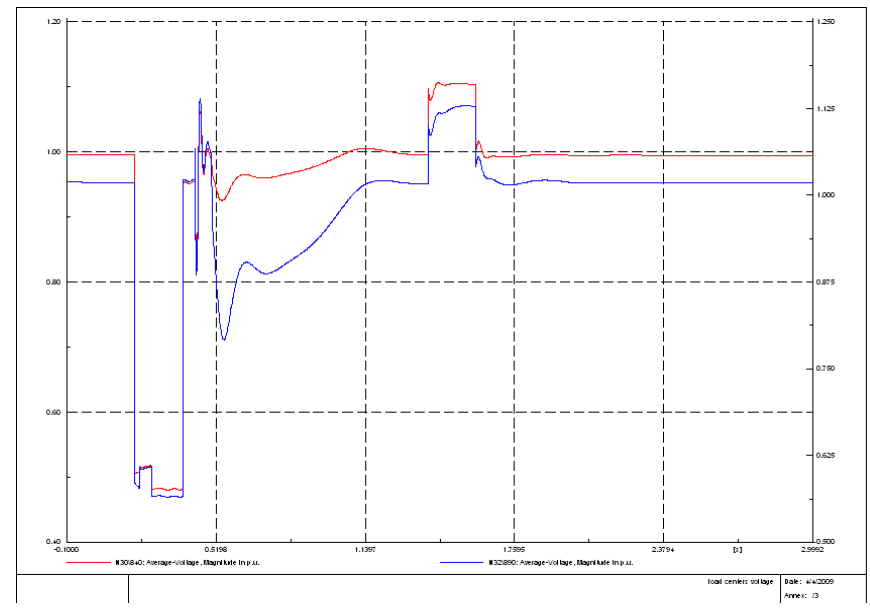

Fig. 7. The voltages of buses 840 and 890 for case $C 2$

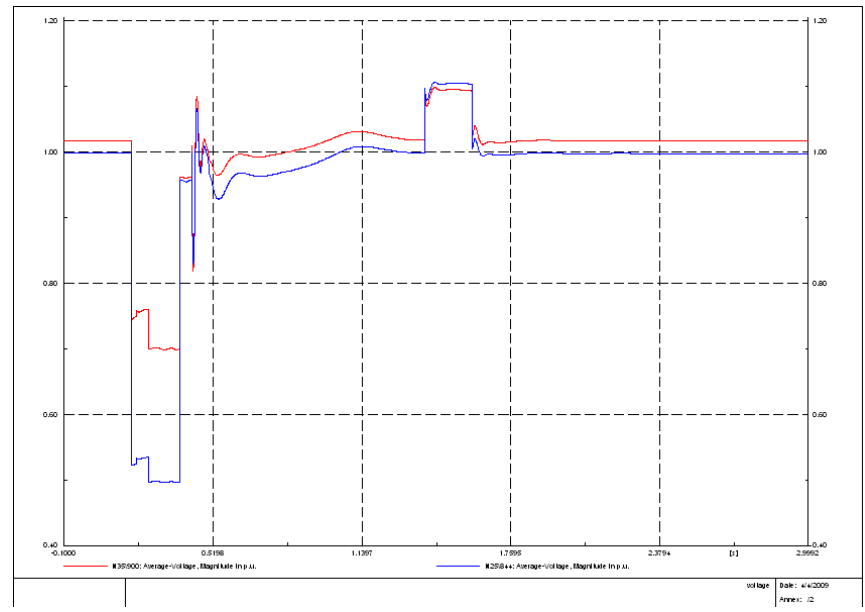

Fig. 8. The voltages of buses 844 and 900 for case C2

From the results shown in Figures7 and 8, the voltage of bus 890 connected with the motor is more affected and it takes more time $(0.5 \mathrm{~s})$ to return its initial state when these disturbances simultaneously occur.

3) Case C3: Based on the condition of case C1, two DFIGs $(0.35 \mathrm{MW})$ are added at buses 856 and 840 ; the load at 840 is adjusted to $0.7 \mathrm{MW}$; the disturbances separately occur and are the same as the disturbances in case $\mathrm{C} 1$. The results are shown in Figures 9 and 10.

By comparing Figures 9 and 10 with Figures 5 and 6, the multiple small-DFIG system bores a less dynamic impact and it takes less time to return to its initial state. Furthermore, the system voltage maintains in the normal range from 0.95 p.u. to 1.05p.u. for a more time.

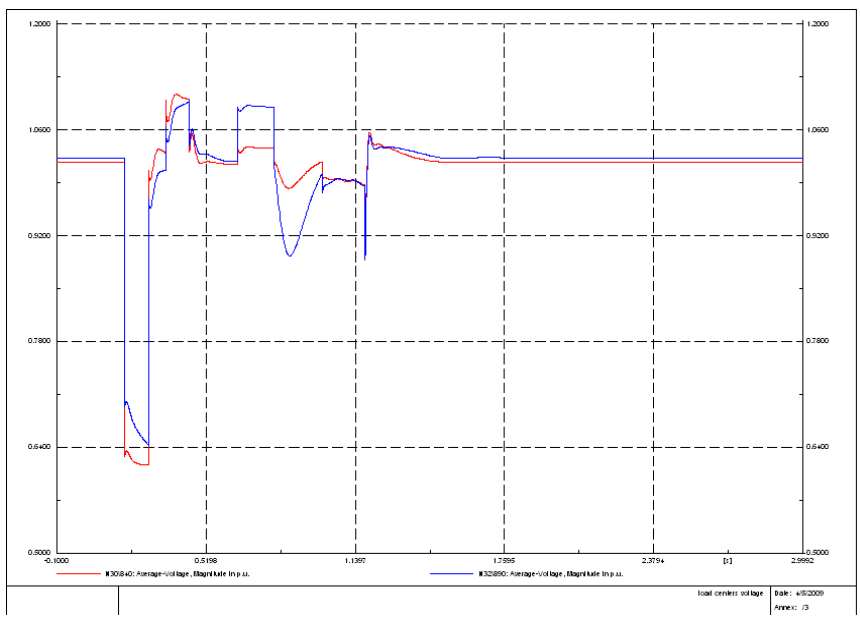

Fig. 9. The voltages of buses 840 and 890 for case C3

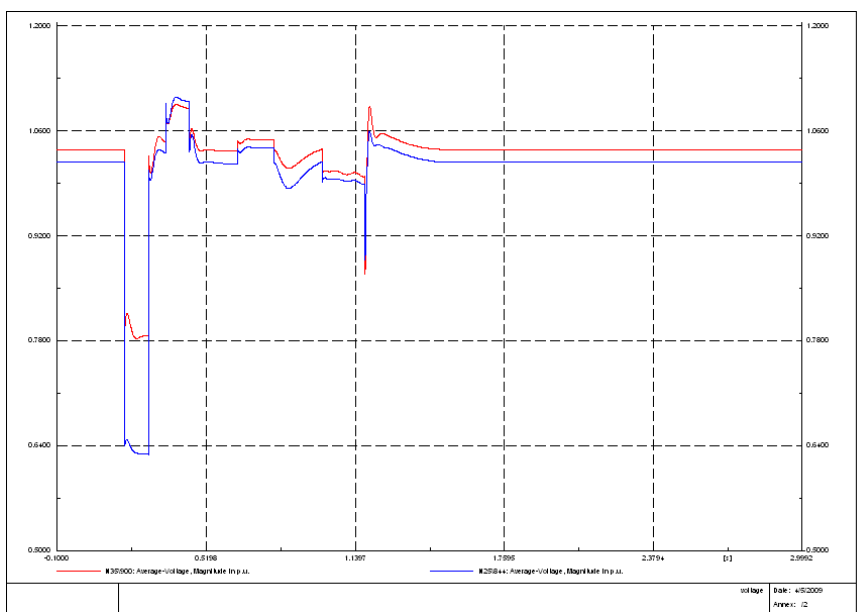

Fig. 10. The voltages of buses 844 and 900 for case C3

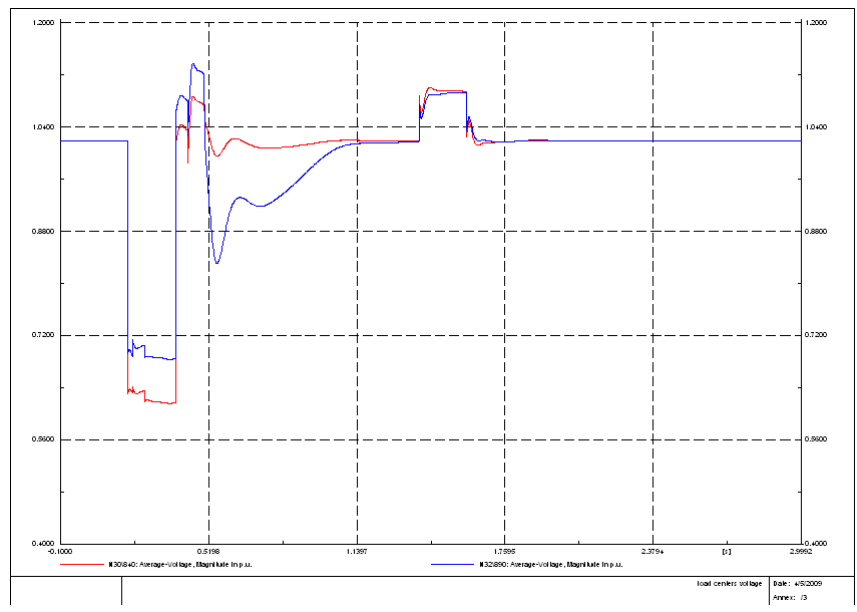

Fig. 11. The voltages of buses 840 and 890 for case C4

4) Case C4: Based on the condition of case C2, two DFIG $(0.35 \mathrm{MW})$ are added at buses 856 and 840 and these disturbances simultaneously occur and are the same as the disturbances in case C2. The results are shown in Figures11 and 12.

Considering the difference between Figures 11 and 12 and Figures 7 and 8, the multiple small-DFIG system has a better stability. The voltage fluctuation is in a smaller range and the 
boundary values are more suitable.

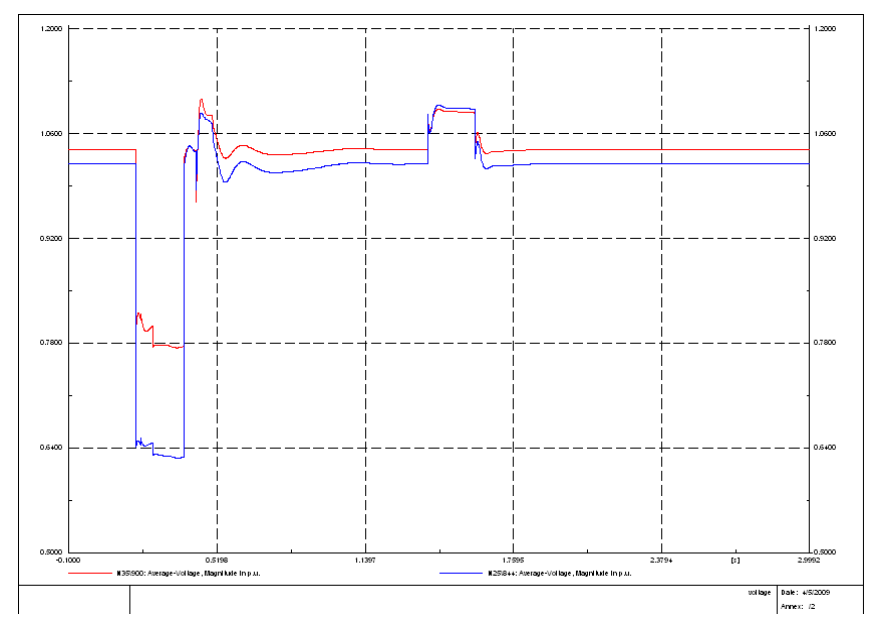

Fig. 12. The voltages of buses 844 and 900 for case C4

\section{CONCLUSION}

This paper has investigated the effects of DFIG-WTs on voltage stability and grid loss of distributions systems under unbalanced load conditions. A new index (system unbalanced voltage variance) has been proposed to evaluate system unbalanced voltage, which is more reasonable and more accurate than that using system average voltage. A new multiobjective optimization function has been provided to calculate the optimal location simultaneously considering the voltage profile and grid loss. Simulations studies have been carried out in DIgSILENT software to examine the impacts of DFIGWTs on the steady-state and dynamic behavior of the IEEE 34-bus test system under unbalanced heavy loading conditions. The optimal location of the single large DFIG-WT in the test system has been determined. Through the comparison between the single large-DFIG system and the multiple small-DFIG system, the latter could provide higher system voltage advancement and almost the same grid loss reduction as the former.

In dynamic simulation, different disturbances, short circuits, cutting load (including constant $\mathrm{Z}$ load and motors), cut-off and cut-in DFIG, have been applied separately or simultaneously. The load-center voltages fluctuate about 0.1 p.u. in this distribution system because of cutting the large load or cut-in DFIG and they affect almost all bus voltages. The dynamic impact of cut-in DFIG is apparently more significant than cut-off DFIG. The motor has a significant role on the local bus voltage and is relatively easily affected by disturbances. The soft-start motor and DFIG technology should be paid more attention in distribution systems. The multiple small-DFIG system bores a less dynamic impact and needs less time to return its initial state than the single largeDFIG system. Moreover, the former voltage fluctuation is in a smaller range and the boundary values are more suitable and the system voltage maintains in the normal range from 0.95 p.u. to 1.05 p.u. for a more time. Therefore, the multiple small-DFIG system has a better stability than the single largeDFIG system.

\section{ACKNOWLEDGMENT}

The authors gratefully acknowledge financial support for this work from the Nebraska Center for Energy Sciences Research.

\section{REFERENCES}

[1] Ryan Wiser, Mark Bolinger "Annual Report on U.S. Wind Power Installation, Cost, and Performance Trends: 2006", http://www.nrel.gov

[2] Philip P. Barker, Robert W. de Mello "Determining the impact of distributed generation on power systems. I. Radial distribution systems", Power Engineering Society Summer Meeting, Vol 3, pp.1645-1656, July, 2000.

[3] Muljadi E., Butterfield C.P., Chacon J., Romanowitz H. "Power quality aspects in a wind power plant", Power Engineering Society General Meeting, pp.8-16, June, 2006.

[4] Hansen A.D., Sorensen P., Janosi L., Bech J. "Wind farm modelling for power quality”, Industrial Electronics Society, 2001. IECON'01. The 27th Annual Conference of the IEEE Volume 3, pp.1959 - 1964, 29 Nov.-2 Dec, 2001

[5] Gardner P. "Flicker from wind farms", BWEA/SERC RAL Workshop on wind energy penetration into weak electricity network, Rutherford, U.K., pp.27-37, 1993.

[6] Ladakakos P.D., Ioannides M.G., Koulouvari M.I. "Assessment of wind turbines impact on the power quality of autonomous weak grids", Harmonics and Quality of Power, 1998. Proceedings. 8th International Conference on Volume 2, pp.900 - 905, 14-16 Oct, 1998.

[7] Seyoum D., Grantham C., Rahman F. "The dynamics of an isolated selfexcited induction generator driven by a wind turbine", Industrial Electronics Society, IECON'2001. The 27th Annual Conference of the IEEE Volume 2, pp.1364 - 1369, 29 Nov.-2 Dec. 2001.

[8] Doyle M.T. "Reviewing the impacts of distributed generation on distribution system protection", Power Engineering Society Summer Meeting, 2002 IEEE, Volume 1, pp.103-105, 25-25 July, 2002.

[9] Aktarujjaman M., Kashem M.A., Negnevitsky M., Ledwich G. "Control Stabilisation of an Islanded System with DFIG Wind Turbine", Power and Energy Conference, 2006. PECon'06, IEEE International 28-29 Nov. 2006 pp.312-317

[10] Muller S., Deicke M. "Doubly fed induction generator systems for wind turbines", IEEE industry application magazine, May/June, 2002.

[11] http://ewh.ieee.org/soc/pes/dsacom/testfeeders.html

[12] http://www.digsilent.com

[13] Jones G.W., Chowdhury B.H. "Distribution system operation and planning in the presence of distributed generation technology", Transmission and Distribution Conference and Exposition, 2008. T\&D. IEEE/PES, pp.1-8, April 2008 